\title{
Clinical attention and assistance profile of patients with amyotrophic lateral sclerosis
}

\author{
Núbia Maria Freire Vieira Lima', Anamarli Nucci²
}

\begin{abstract}
Objective: To evaluate the functional status of amyotrophic lateral sclerosis (ALS) patients diagnosed at this institution; to analyze hospital and palliative care; to identify patients' knowledge about home care and supportive resources. Method: Twenty-nine patients were evaluated on the ALSFRS-R scale and two semi-structured questionnaires, at the start of the study and every four months thereafter for 1 year. Results: ALSFRS-R score was $30.1 \pm 11.5$ initially and $24.4 \pm 10.5$ at 1 year. There was an increase in use of physiotherapeutic care and adaptive aids. The primary caregivers were spouses (55.2\%), parents/children/cousins (20.7\%), friends (10.3\%) and private nurses (3.5\%); $10.3 \%$ of patients had no caregivers. Basic ALS patient care was provided by the public health system. Conclusion: ALS patients' multidisciplinary care was provided by UNICAMP hospital and its outpatient clinics and, in some patients, complemented by a private health plan or personal expenditure. Few ALS patients were aware of the possibility of home nursing. It is necessary to implement national and regional public home nursing in addition to multidisciplinary specialized care of ALS patients.
\end{abstract}

Key words: amyotrophic lateral sclerosis, ALSFRS-R scale, home nursing, caregivers, health system.

\section{Perfil clínico e assistencial de pacientes com esclerose lateral amiotrófica}

\section{RESUMO}

Objetivo: Avaliar o estado funcional de um grupo de pacientes com esclerose lateral amiotrófica (ELA) na instituição; analisar a assistência hospitalar e de cuidados paliativos; identificar o conhecimento dos pacientes sobre potenciais recursos de assistência e home care. Método: Vinte e nove pacientes foram submetidos à escala ALSFRS-R e dois questionários semi-estruturados no início do estudo e a cada 4 meses, por um ano. Resultados: $O$ escore inicial da ALSFRS-R foi $30,1 \pm 11,5$ e o final $24,4 \pm 10,5$, tendo sido necessária maior assistência fisioterápica e uso de órteses. O cuidador primário foi:

\section{Correspondence}

Anamarli Nucci

Departamento de Neurologia

Universidade Estadual de Campinas / UNICAMP 13083-970 Campinas SP - Brasil E-mail: anucci@ni.hc.unicamp.br

\section{Support}

The study had the support of CAPES (Comissão de Aperfeiçoamento de Pessoal de Nível Superior)

Received 16 August 2010

Received in final form 3 November 2010 Accepted 16 November 2010 cônjuge (55,2\%), pais/filhos/primos (20,7\%), amigos (10,3\%), particular (3,5\%); 10,3\% não tinham cuidador. A assistência na ELA baseou-se no sistema público de saúde. Conclusão: O cuidado multidisciplinar ao paciente com ELA fez-se através do hospital e ambulatórios UNICAMP e, para alguns pacientes, houve complementação por plano de saúde e custeio pessoal. A maioria dos pacientes desconhecia a possibilidade de assistência domiciliar na ELA. Faz-se necessária a estruturação nacional e regional da assistência domiciliar pública em ELA, acrescida ao trabalho multidisciplinar especializado.

Palavras-chave: esclerose lateral amiotrófica, escala ALSFRS-R, assistência domiciliar, cuidador, sistema de saúde.

${ }^{1}$ Ms, Physiotherapist, Department of Neurology, School of Medical Sciences, State University of Campinas (UNICAMP), Campinas SP, Brazil; ${ }^{2}$ Associate Professor, Department of Neurology, School of Medical Sciences, UNICAMP. 
Amyotrophic lateral sclerosis (ALS) is a progressive and fatal disease due to degeneration of upper and lower motor neurons ${ }^{1,2}$. ALS has a worldwide annual incidence of approximately 1.5 to 2 cases $/ 100,000$ and prevalence of $6-8$ cases $/ 100,000^{3,4}$. In Brazil, the estimated prevalence varies from 0.9 to 1.5 cases/100,000 and the incidence varies from 0.2 to 0.32 cases per 100,000 inhabitants/year ${ }^{5}$. Previous studies have shown that men are twice as likely to suffer from ALS as women ${ }^{6}$ and a Brazilian series ${ }^{7}$ revealed a female to male ratio of 1:1.8.

ALS is considered a paradigm of non-oncologic disease for palliative care ${ }^{8}$. Its complications must be treated symptomatically by various health professionals ${ }^{9}$. In Brazil, the Ministry of Health established the Clinical Protocol and Therapeutic Guidelines for the treatment of ALS in November $2002^{10}$. There is also law number 10,424, dated April 2002, which established the Home Nursing Program within the SUS (Brazilian public health system). However, the law did not specify for which particular diseases the program can be used. Although home nursing does not replace hospital care, it should always be used to ensure patients' comfort and to humanize treatments ${ }^{11}$.

Hughes et al. ${ }^{12}$ reported on the importance of quantifying health services experience of patients with neuromuscular diseases, including ALS. They also commented on the importance of patient knowledge about home nursing and their rights as patient. These informations may aid in the restructuring of services.

The aims of this study were: [1] to evaluate hospital care and home nursing of ALS patients, [2] to quantify the functional status of patients, and [3] to identify patients' knowledge about home assistance.

\section{METHOD}

We designed a prospective, descriptive study with a longitudinal component, performed in accordance with the Declaration of Helsinki and approved by the Ethics and Research Committee of the UNICAMP (protocol number 588/2005).

\section{Study population}

Patients with ALS were recruited at the Neuromuscular Diseases outpatient clinics at UNICAMP and enrolled in order of arrival from February 2006 to August 2007. To be included in the study patients must have been diagnosed with definite or probable ALS as defined by El Escorial criteria ${ }^{13}$. Both male and female patients at any disease stage were recruited. Participating patients were required to sign an informed consent form. Exclusion criteria included associated neurological or orthopedic diseases or an inability to read in order to answer the questionnaires.

\section{Instruments}

ALS Functional Rating Scale Revised (ALSFRS-R). The scale assesses 12 items: speech, swallowing, salivation, writing, eating, clothing/hygiene, transferring to bed/linen setting, walking, climbing stairs, dyspnea, orthopnea, and respiratory insufficiency. The score ranges from 0 (completely disable) to 48 (normal) ${ }^{14}$.

Two semi-structured questionnaires were also used. The first one was modified from Albert et al. ${ }^{15}$ and addresses home nursing, assistance therapies (physical, occupational and speech therapies), adaptive aids (nonverbal communication, braces, canes, orthosis, walkers, and wheelchairs), paid home nursing services (private nurse or other worker), social and psychological support (psychotherapy or ALS group therapy), rights of home nursing patients, technological interventions (endotracheal aspiration, tracheostomy, mechanical ventilation, invasive or noninvasive, IMV or NIV, respectively), pharmacological interventions (conventional, for example, the use of riluzole or vitamin E, or alternative therapies such as acupuncture, homeopathy, herbal medicine or Ayurvedic medicine).

The second questionnaire was adapted from Krivickas et al. ${ }^{9}$ and addressed to patients and primary caregivers. It consists of questions concerning home nursing, functional status, satisfaction about healthy care, and expenses on home nursing or hospital services (expenses in Brazilian currency: real - $\mathrm{R} \$$ ).

Both questionnaires were completed at the beginning of the study and every 4 months thereafter for 12 months.

\section{Statistical analysis}

Descriptive analysis of categorical and continuous variables was done. ANOVA compared the four ALSFRS-R scores obtained by the patients. Generalized estimation equation was used to compare each item of assistance in the four time periods evaluated. Spearman correlation coefficient tested the correlation between the number of items of assistance used by patients and ALSFRS-R scores. The level of significance was stated as $<5 \%$. Statistical data was performed with SAS System for Windows version 9.1.3, SPSS for Windows version 10.0 and Microcal Origin version 5.0.

\section{RESULTS}

Thirty-five individuals were invited to participate in the study, but 29 gave their consent. Their demographic characteristics, as determined in the initial assessment, are shown in Table 1. In the second assessment, 26 patients remained in the study; in the third assessment 22 and, in the last assessment, 21 patients remained. Over the period of the study, deaths occurred in $27.6 \%$ of pa- 
Table 1. Demographic and social economic characteristics in the first assessment $(n=29)$.

\begin{tabular}{lccc}
\hline Variables & Values & mean \pm SD & min; max \\
\hline Gender (F:M) & $10: 19$ & & - \\
Age (years) & & $49.2 \pm 12.2$ & $20 ; 70$ \\
Duration of symptoms (months) & $34.9 \pm 26.7$ & $5 ; 111$ \\
ALS presentation (A/B/Mi) & $22 / 2 / 5$ & & - \\
Family income (minimum wage) & & $4.9 \pm 2.39$ & $1 ; 9$ \\
Schooling & 15 & \\
$\quad$ Completed elementary & 10 & \\
$\quad$ Completed high school & & & \\
$\quad$ Incomplete or complete higher & 4 & \\
$\quad$ Education & 2 & \\
Use of ABRELA & 12 & \\
Local housing & 14 & \\
$\quad$ Campinas & 3 & \\
Other cities (SP) & & \\
$\quad$ Others states & & \\
ALSFRS-R & & \\
\hline F: female; M: male; A: apendicular; B: bulbar; Mi: mixed; ABRELA: ALS Brazilian Association; ALSFRS-R: \\
Amyotrophic Lateral Sclerosis Functional Rating Scale-Revised; min: minimum; max: maximum.
\end{tabular}

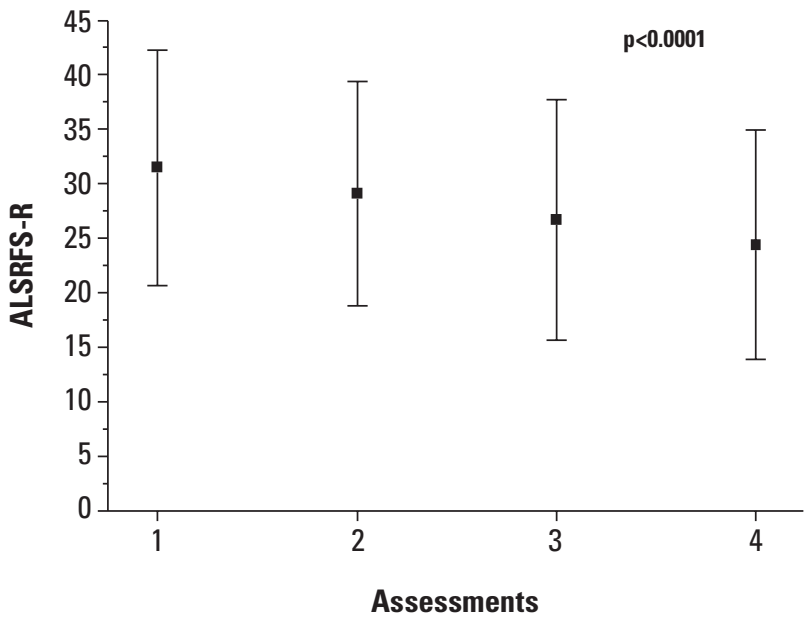

Figure. Mean value and standard deviation of the scale ALSFRS-R in each assessment $(n=21)$.

tients. Descriptions were based on $n=29$ and statistical comparisons were based on $\mathrm{n}=21$.

The ALSFRS-R scores are shown in Figure. We detected a correlation between total ALSFRS-R score and the amount of care in the first assessment $(r=-0.62$, $\mathrm{p}=0.001$ ), but no statistically significant correlation was found for the subsequent assessments.

Table 2 shows the changes in care between the first and fourth assessments. There was an increase in the amount of care provided to patients with ALS after 12 months, with the change reaching statistical significance for physical therapy services and for the use of braces and orthosis $(\mathrm{p}<0.001)$.

In the first assessment, we noticed eight patients who had a health insurance plan, two of which were in physical therapy or speech therapy and one that had home nursing health coverage. Two patients paid all the costs of home therapies, and four received healthy assistance exclusively at UNICAMP.

During the study, two patients had indication to NIV and two were hospitalized to adapt to bi-level positive airway pressure. The NIV devices were provided by the Institute of Sleep (Federal University of São Paulo) and were used at home. One patient had worsening of pulmonary condition and was reassessed in the hospital.

Table 3 summarizes data from the questionnaires. The primary caregivers consisted of spouses (55.2\%), children (10.3\%), parents (6.9\%), friends (10.3\%), cousins (3.5\%) and hired caregivers that helped with feeding, using the computer, bathing and dressing. $10.3 \%$ of patients had no caregivers. Among the activities that patients wanted to be able to perform were working, boxing, bike riding, dancing and walking at the mall.

\section{DISCUSSION}

In this study, there was a predominance of male patients (1.9:1) with a mean age of 49.2 years (extremes 20 and 70 years). The mean duration of symptoms was 34.9 months (extremes 5 and 111 months). Other studies of the Brazilian population showed a similar mean age as this study ${ }^{5,16}$. All patients had the sporadic form of ALS, 
Table 2. Care aspects of patients with ALS.

\begin{tabular}{|c|c|c|}
\hline Items & $1^{\text {st }}$ assessment $(n=21)$ & $4^{\text {th }}$ assessment $(n=21)$ \\
\hline \multicolumn{3}{|l|}{ Assistance therapies } \\
\hline Physical therapy and hospital or outpatient & $6(28 \%)$ & $10(47 \%)$ \\
\hline Occupational therapy & 0 & $1(4.7 \%)$ \\
\hline Speech therapy (outpatient) & $1(4.7 \%)$ & $2(9.5 \%)$ \\
\hline \multicolumn{3}{|l|}{ Adaptive aids } \\
\hline Augmentative communication & $3(14 \%)$ & $3(14 \%)$ \\
\hline Brace/cane/ortosis & $4(19 \%)$ & $11(52 \%)$ \\
\hline Walker & 0 & $5(23.8 \%)$ \\
\hline Wheelchair & $7(33 \%)$ & $11(52 \%)$ \\
\hline \multicolumn{3}{|l|}{ Psychosocial care } \\
\hline Psychotherapy & $3(14 \%)$ & $5(23.8 \%)$ \\
\hline ALS support group & $2(9.5 \%)$ & $2(9.5 \%)$ \\
\hline Health plan & $8(38 \%)$ & $8(38 \%)$ \\
\hline \multicolumn{3}{|l|}{ Technological interventions } \\
\hline Nasogastric tube & 0 & $1(4.7 \%)$ \\
\hline Tracheostomy & 0 & $1(4.7 \%)$ \\
\hline Noninvasive ventilation & $2(9.5 \%)$ & $4(19 \%)$ \\
\hline Invasive mechanical ventilation & 0 & $1(4.7 \%)$ \\
\hline \multicolumn{3}{|l|}{ Pharmacological interventions } \\
\hline Conventional pharmacology & $21(100 \%)$ & $21(100 \%)$ \\
\hline Alternative therapies & $1(4.7 \%)$ & $1(4.7 \%)$ \\
\hline \multicolumn{3}{|l|}{ Homecare services } \\
\hline Paid caregiver & $1(4.7 \%)$ & $1(4.7 \%)$ \\
\hline Nursing* & $1(4.7 \%)$ & $1(4.7 \%)$ \\
\hline Physiotherapy* & $2(9.5 \%)$ & $4(19 \%)$ \\
\hline Speech Therapy* & $1(4.7 \%)$ & $1(4.7 \%)$ \\
\hline Hospitalization* & $1(4.7 \%)$ & $1(4.7 \%)$ \\
\hline Home emergency service* & $1(4.7 \%)$ & $1(4.7 \%)$ \\
\hline Funeral service contract & $1(4.7 \%)$ & $1(4.7 \%)$ \\
\hline \multicolumn{3}{|l|}{ Patient's rights } \\
\hline Attorney / Lawyer & 0 & 0 \\
\hline
\end{tabular}

*Provided by the health plan.

Table 3. Estimated data through questionnaires $(n=29)$.

\begin{tabular}{lc}
\hline Items & Value (\%) \\
\hline Knowledge of the possibility of home nursing & $11(37.9 \%)$ \\
No satisfaction with the process of care (waiting time in medical consultation, & 11 \\
difficulties in accessing physical and speech therapy services) & 6 \\
Problems to transport the patient & 4 \\
Unavailability of caregivers for medical appointments & 150.00 \\
Average spending per month for physical therapy and / or outpatient & \\
speech and / or household (Brazilian real - $R \$$ ) ( $n=6)$ & 44.80 \\
Transportation (monthly - R\$) & 87.30 \\
Private expenses with assistive devices ( $n=19)(R \$)$ & 6.2 \\
Average time spent by the primary caregiver at home (hours/day)
\end{tabular}


including the youngest one. Castro-Costa et al. ${ }^{7}$ reported that $21.1 \%$ of their cases had the juvenile form of ALS.

From the ALSFRS-R scores at the onset of the study, it can be inferred that there was heterogeneity in the severity of ALS symptoms in the group. This suggests a need for individualized treatment plans that take into account each stage of the disease and its complications. In fact, individualized treatment plans were basic components of the guidelines developed by the Quality Standards Subcommittee of the American Academy of Neurology ${ }^{17}$ and by the European Ethics Committee ${ }^{18}$.

Another aspect of ALS is the progression of motor deficits. Hence, the ongoing availability of information to patients and families about the presence of multiple professions in their palliative treatment is important. It is possible that patients' level of education influences their pursuit of knowledge about ALS, the possibilities of care and their rights as citizens. In this study, $62.1 \%$ of patients were unaware of the possibility of home nursing, yet $48 \%$ had completed elementary school level. Rodrigues et al. ${ }^{19}$ also found lack of knowledge about rights of ALS patients in $62.5 \%$ of Portuguese families, despite $78.9 \%$ of their patients having completed basic schooling. Albert et al. ${ }^{15}$ found an average of 14.2 years of schooling for their USA ALS patients. In this study, $13.7 \%$ of patients had started or completed higher education, whereas Rodrigues et al. ${ }^{19}$ reported $5.3 \%$ of patients completing the same level of schooling.

The patients who lived outside the city of Campinas (58\%) may have influenced the report of transportation difficulties to UNICAMP. Another complaint reported in the initial questionnaire was the long waiting time prior to receiving medical consultation. This problem was resolved by the referral team because priority was given to ALS patients.

The spouse was the primary caregiver in $55.2 \%$ of patients. By including parent and child caregivers, our data reveals that $72.4 \%$ of patients had immediate family as primary caregivers. Previous studies have shown that spouses serve as primary caregivers in $67-73.4 \%$ of patients ${ }^{9,19,20}$. Hirano et al. ${ }^{21}$ reported that family members were the only caregivers who provided daily support in $65.3 \%$ of their ALS patients.

We found $13.5 \%$ of caregivers were friends or cousins of patients, whereas Krivickas et al. ${ }^{9}$ found $2 \%$ who were not immediate family. The help of friends or people outside the family nucleus reveals the sense of solidarity among community members to the patient with ALS. After reviewing the care of a female Brazilian patient with ALS, Borges et al. ${ }^{22}$ showed that, not only had the disease reorganized the functions of family members, but it also had influenced friends and neighbors, who helped because of solidarity and not due to any formal obligations to care for the patient. In this study, $10.3 \%$ of pa- tients had no caregivers. These patients are likely to face great difficulties during the course of their disease. Krivickas et al. ${ }^{9}$ observed that caregivers of patients who were not receiving home nursing care were spending, on average, 4 hours/day supporting the patient, whereas in our series caregivers spent 6.2 hours/day.

As expected, the ALSFRS-R score revealed a decline in functional motor capacities and an increase in dependency of our patients on others for assistance. Consequentially, periodic reassessment of palliative therapeutic measures, particularly physiotherapy, is need for patients, as shown previously ${ }^{23}$ with an increase in the use of adaptive aids and orthosis as the disease progresses. Considering the multidisciplinary approach to the treatment of ALS ${ }^{17,18,24}$, physical therapy was the most common treatment at both the beginning (28\%) and end (47\%) of the study. Albert et al. ${ }^{15}$ reported that, in the first year after diagnosis, $49.4 \%$ of their patients were treated with physiotherapy, 33.3\% with occupational therapy and $34.4 \%$ with speech therapy.

The number of deaths in this study reflects the rapid progression of ALS. Albert et al. ${ }^{15}$ found that $53.8 \%$ of patients died after 1 year of follow-up and among patients with up to 1 year of follow-up of a confirmed diagnosis, 9.3\% were using NIV in the first assessment, but 28\% were using NIV after 1 year.

A significant correlation between the severity of symptoms and provision of palliative services was observed with the first evaluation, but not the others. Studies ${ }^{9,25}$ have shown similar results and, as with our study, also revealed the gap between the need for palliative care and the ability to obtain services or resources.

Assistance to ALS patients was provided by care at the hospital and outpatient clinics, primarily within the SUS. Additionally, for a small number of patients, we observed coexisting care for some services provided by a health plan and private services. From these results, we emphasize that there is a lack of organized publiclyfunded home care for ALS patients.

In the "Brazilian Clinical Protocol and Therapeutic Guidelines for the Treatment of ALS"10 there are two recommendations: [1] multidisciplinary care and [2] to minimize hospital stay for patients. Regarding the first item, there was an agreement between the official document and our findings. Depending on clinical needs, ALS patients had the assistance of neurologists, pulmonologists, nurses, physiotherapists, psychologists, speech and occupational therapists and nutritionists. There is no formal home nursing linked to UNICAMP that can minimize the duration of hospital stay of ALS patients. Healthcare professionals discussed palliative guidelines with patients and caregivers in each outpatient appointment and kept an open access to the healthcare team. Special attention was given to patients with the most severe motor impairment. In these circumstances, home care teams 
could help to the patient avoid repeated trips to the hospital, preventing transport difficulties, poorer quality of life and delayed care.

The shortcomings in the public system may require the patient to seek for personal payment for equipment, adaptive aids, private physical or speech therapies, or even hiring of private home nursing. Difficulties in providing the various devices for patients with ALS are not exclusive to Brazil. In Scotland, the state also has an obligation to provide comprehensive health care for ALS, yet the processes of acquisition and availability of these materials are slow ${ }^{25}$. Non-governmental organization, like ALS Brazilian Association (ABRELA) is also not completely able to meet the demand and expectations of all patients and family members. $65 \%$ of patients supported by ABRELA acquired their adaptive aids for mobility with personal expenses ${ }^{26}$.

The patients' expenses in this study were associated with physical and speech therapies, home care, outpatient clinical assistance, and acquisition of devices for locomotion. In the USA, spending on home nursing varied from US\$ 15 to US\$ 800 per week/ patient ${ }^{9}$. In Japan, health plans do not cover the entire cost of IMV; therefore, the estimated monthly costs for $48.3 \%$ of ALS families surpassed US $\$ 467$ per patient ${ }^{21}$. Krivickas et al. ${ }^{9}$ reported that, in Ohio, health plans provide $100 \%$ of hospital costs and only $63 \%$ of home nursing costs. We found eight patients (27.5\%) with a health insurance plan. Among them, two had sessions of physical and speech therapies at an outpatient clinic, and one was receiving treatment at home. The others had no palliative care covered by their health plan.

In the USA, a list of steps in palliative care of ALS is offered to $90 \%$ of patients ${ }^{18}$, and they may choose the approach according their wishes. The most common and crucial step in palliative care refers to the use of IMV for respiratory failure. Therefore, treatment approaches should be periodically reviewed and steps should be taken to ensure that they are in accordance with the patient's wishes ${ }^{18,27}$, including addressing the question of cardiac resuscitation. Communication between hospital and home care teams would facilitate sharing of information about the various stages of ALS care and its consequences.

In conclusion, ALSFRS-R was an adequate instrument to detect motor function decline. ALS patients received their care primarily at UNICAMP hospital and multidisciplinary outpatient clinics not connected to any public home nursing organization. This assistance was eventually complemented by a health plan or patients' own expenditures. Formal and informal communications among health professionals concerning the patients' care articulated strategies for the best individual care. Few patients and family members knew about the possibility of home nursing for ALS from which they could benefit.
Improvement of the public health system for ALS patients is needed.

\section{REFERENCES}

1. Beghi E, Logroscino G, Chiò A, et al. The epidemiology of ALS and the role of population-based registries. Bioch Biophy Acta 2006;1762:1150-1157.

2. Majoor-Krakauer D, Willems PJ, Hofman A. Genetic epidemiology of amyotrophic lateral sclerosis. Genet Epidemiol 2003;63:83-101.

3. Barber SC, Mead RJ, Shaw PJ. Oxidative stress in ALS: a mechanism of neurodegeneration and a therapeutic target. Bioch Biophys Acta 2006; 1762:1051-1067.

4. Brooks BR. Clinical epidemiology of amyotrophic lateral sclerosis. Neurol Clin 1996;14:399-420.

5. Dietrich-Neto F, Callegaro D, Dias-Tosta E, et al. Amyotrophic lateral sclerosis in Brazil. 1998 National Survey. Arq Neuropsiquiatr 2000;58:607-615.

6. Mitchell JD. Amyotrophic lateral sclerosis: toxins and environment. Amyotroph Lateral Scler Other Motor Neuron Disord 2001;1:235-250.

7. Castro-Costa CM, Oriá RB, Vale OC, et al. Motor neuron diseases in the University Hospital of Fortaleza (Northeastern Brazil). Arq Neuropsiquiatr 2000;58:986-989.

8. Borasio GD, Miller RG. Clinical characteristics and management of ALS. Sem Neurol 2001;21:155-166.

9. Krivickas LS, Shockley L, Mitsumoto H. Home care of patients with amyotrophic lateral sclerosis. J Neurol Sci 1997;152:69-82.

10. Ministério da Saúde. Protocolo clínico e diretrizes terapêuticas para o tratamento da esclerose lateral amiotrófica. Disponível em sna.saude. gov.br/legisla/legisla/informes/SAS_P913_informes.doc. Acesso em 13 de fevereiro de 2008.

11. Silva KL, Sena R, Leite JCA, et al. Internação domiciliar no Sistema Único de Saúde. Home care in the Brazilian National Health System (SUS). Rev Saúde Pública 2005:39:391-397.

12. Hughes RA, Sinha A, Higginson I, et al. Living with motor neurone disease: lives, experiences of services and suggestions for change. Health Soc Care Community 2003;13:64-74

13. Brooks BR, Miller RG, Swash M, et al. World Federation of Neurology Research Group on Motor Neuron Diseases, El Escorial revisited: revised criteria for the diagnosis of amyotrophic lateral sclerosis. Amyotroph Lateral Scler Other Mot Neuron Disord 2000;1:293-299.

14. Guedes K, Pereira C, Pavan K, et al. Cross-cultural adaptation and validation of ALS Functional Rating Scale-Revised in Portuguese language. Arq Neuropsiquiatr 2010;68:40-47.

15. Albert SM, Murphy PL, Del Bene ML, et al. Prospective study of palliative care in ALS: choice, timing, outcomes. J Neurol Sci 1999;169:108-113.

16. Werneck LC, Bezerra R, Neto OS, et al. A clinical epidemiological study of 251 cases of amyotrophic lateral sclerosis in the south of Brazil. Arq Neuropsiquiatr 2007;65:189-195.

17. Miller RG, Rosenberg JA, Gelinas DF, et al. Practice parameter: the care of the patient with amyotrophic lateral sclerosis (an evidence-based review). Neurology 1999:52:1311-1323.

18. Radunovic A, Mitsumoto H, Leigh PN. Clinical care of patients with amyotrophic lateral sclerosis. Lancet Neurol 2007:6:913-925.

19. Rodrigues G, Winck JC, Silveira F, et al. Avaliação sociológica de doentes com esclerose lateral amiotrófica. Rev Port Pneumol 2002;8:645-665.

20. Marchese S, Lo Coco D, Lo Coco A. Outcome and attitudes toward home tracheostomy ventilation of consecutive patients: a 10-year experience. Respir Med 2008;102:430-436.

21. Hirano YM, Yamazakia Y, Shimizub J, et al. Ventilator dependence and expressions of need: a study of patients with amyotrophic lateral sclerosis in Japan. Soc Sci Med 2006;62:1403-1413.

22. Borges CF. Dependência e morte da "mãe de família": a solidariedade familiar e comunitária nos cuidados com a paciente de esclerose lateral amiotrófica. Psicol Estudo 2003:8:21-29.

23. Lima NMFV, Oberg TD, Teixeira LC, et al. Independência funcional em portadores de esclerose lateral amiotrófica. In: I Inter Cobraf. Rev Bras Fisioter São Carlos-SP, 2006.

24. Traynor BJ, Alexander M, Corr B, et al. Effect of a multidisciplinary amyotrophic lateral sclerosis (ALS) clinic on ALS survival: a population based study, 1996-2000. J Neurol Neurosurg Psychiatry 2003;74:1258-1261.

25. Van Teijlingen ER, Friend E, Kamal AD. Service use and needs of people with motor neurone disease and their careers in Scotland. Health Soc Care Community 2001;9:397-403.

26. Anequini IP, Pallesi JB, Fernandes $E$, et al. Avaliação das atividades da ABRELA: orientações oferecidas, expectativas atingidas? Rev Neurocienc 2006:14:191-197.

27. Borasio GD, Voltz R, Miller RG. Palliative care in amyotrophic lateral sclerosis. Neurol Clin 2001;19: 829-847. 